\title{
Assessment of Response Modification Factor of Open Steel Platform Structures Subjected to Seismic Loads
}

\author{
Yasser S. Salem ${ }^{(凶)}$, Lisa Wang, and Germaine Aziz \\ Civil Engineering Department, Cal Poly Pomona, Pomona, CA, USA \\ \{ysalem,ylwang\}@cpp.edu, germaineaziz@gmail.com
}

\begin{abstract}
Open frame steel platforms (hereinafter "OFS platforms") are largely utilized in manufacturing and industrial facilities. OFS platforms are built around the refinery attached to the infrastructure to provide access for maintenance work. Nonlinear static pushover analysis and nonlinear dynamic time history analysis are conducted to study the inelastic behaviour of these frames. The analysis accounts for their unique detailing especially to elements that contribute to energy dissipation during major seismic events. Maximum inter-story drift and peak global roof drift were adopted as critical response parameters. The results show that the reserve strength of structure is less than that prescribed by the ASCE7-08 for ordinary concentric braced frame systems.
\end{abstract}

\section{Introduction}

Modal building codes such as ASCE/SEI 7-10, Minimum Design Loads for Buildings and Other Structures do not currently list a specific R factor for Open Frame Structure (OFS) platforms. This studies main objective is to determine the $\mathrm{R}$ factor for OFS platforms and introduce them into the building codes through numerical simulations to study the performance of these structures under major seismic events.

The main objective behind this study is to develop a more realistic value for the $\mathrm{R}$ factor that can be used by practicing engineers to design sturdier OFS platforms. The ultimate goal is to reduce the risk of damage of the OFS platforms or the infrastructures they are attached to during a major seismic event. Also, knowing the appropriate $\mathrm{R}$ factor specific of OFS platforms will help in designing such a structure that has enough capability to dissipate energy coming from outside forces (i.e. earthquake) without having excessive member sizes.

This paper will use nonlinear analysis to examine the unique detailing requirements of OFS platforms and to determine what limitations are appropriate for this type of platform by (1) utilizing nonlinear static analysis, to determine the ultimate lateral load resistance on the OFS platforms; and (2) utilizing nonlinear dynamic analysis to evaluate the structure's energy dissipation capacity and characteristics during an earthquake. This study utilizes current data from the United States Geological Survey (hereinafter "USGS") for earthquake ground accelerations and various model structures with varying levels in order to compare the calculated results with current $\mathrm{R}$ factors 
being utilized in current designs for OFS platforms. The results obtained from the analysis conducted will be used to develop an R factor for OFS platforms.

\section{Open Frame Steel Structure}

OFS platforms are largely utilized in manufacturing and industrial facilities. Commonly, they are found in large refineries where they are used to process crude oil and power plants. These platforms are steel structures that consist of steel towers carrying maintenance platforms. Figure 1 are examples of open frame steel platform structures used in refineries today.

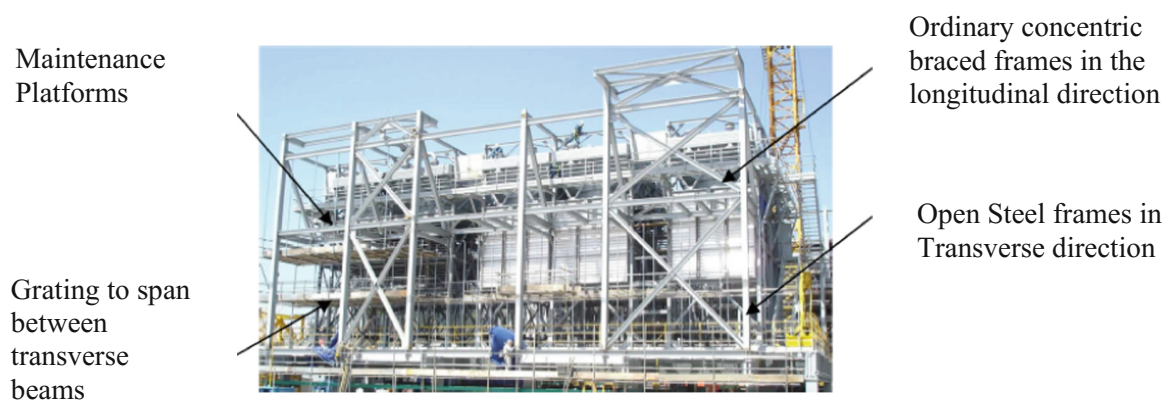

Fig. 1. Example of open frames steel structure

In these examples, "[T]he lateral resisting system for the open steel frames and the steel tower are formed of ordinary concentric brace frames. Lateral stability of the platforms is provided by horizontal braced members below the grating elevation. Due to constructability consideration, [it appears that] all steel connections are bolted at the field using bearing type connection (Salem)."

Currently, an R factor for OFS platforms has not been codified in a building code resource such as the ASCE/SEI 7-10, Minimum Design Loads for Buildings and Other Structures. The current practice is to estimate the seismic loads for these structures using parameters of similar building-type structures. Most commonly, for these OFS platforms, since they are made of steel and are braced frames with lateral force resisting systems, practicing engineers usually use the $\mathrm{R}$ factors of other systems mainly building frame system which is significantly different in terms of geometry and detailing from OFS where platforms have no floor or roof diaphragms with lumped masses. Therefore, building code design equations are not suitable to predict their performance during earthquakes. In this paper, the focus is on the direct comparison of ordinary concentric braced frame (OCBF) or special concentric braced frames (SCBF) $\mathrm{R}$ factors which are 3.25 and 6.0, respectively with the performance of the OFS. 


\section{Response Modification Factor}

Conventional seismic design in most modal codes is force-based, with a final check on structural displacements. The force-based design is suited to design for actions that are permanently applied. The seismic design follows the same procedure, except for the fact that inelastic deformations may be utilized to absorb certain levels of energy leading to a reduction in the forces for which structures are designed. This leads to the creation of the Response Modification Factor (R factor); the all-important parameter that accounts for over-strength, energy absorption, and dissipation as well as the structural capacity to redistribute forces from inelastic highly stressed regions to other less stressed locations in the structure. This factor is unique and different for different type of structures and materials used. Hence, classification of Response Modification Factor for various structural systems is extremely important in order to do an evaluation based on demand and capacity of the structure (Fig. 2 and Table 1).

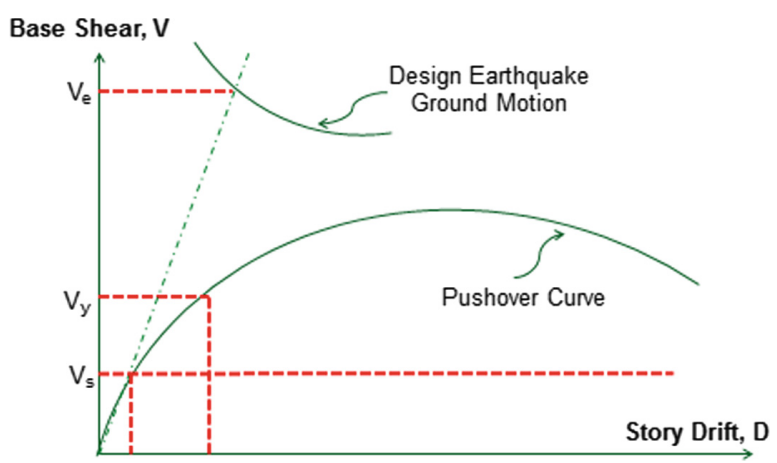

Fig. 2. Seismic performance factors as illustrated by commentary to the NEHRP recommended provisions (FEMA-450)

The Response Modification Factor ( $\mathrm{R}$ factor) reduces the seismic force to a design level as it is assumed that structures contain reserve strength, an extra energy dissipating capability as observed from previous earthquakes (ATC-19). This extra capability is based on a structure's ductility, an ability to absorb energy by deforming. This relationship is illustrated by an inelastic force-deformation curve as seen in Fig. 3. The diagonally rising line represents the linearly increasing deformation as the force increases. The linearly elastic response goes up until the point of Ve, elastic seismic force - which is the base shear if the structure were to maintain an elastic behavior. In reality, structures lose their ability to deform proportionally to the applied force. After point $\mathrm{Vd}$, design base shear, the structure may have larger deformations yet dissipate lesser force. At this given stage, plastic hinges begin to form, which identify the points where the energy dissipating ability of the structure drops step by step until the structure's maximum seismic force, Vy, is reached (ATC-19).

An elastic design would assume the structure to have a linear force-deformation relationship, and thus be able to deform less and dissipate less energy. On the other hand, inelastic design acknowledges the ability to continuously deform and keep on 
Table 1. Structure configuration

\begin{tabular}{|c|c|c|c|c|}
\hline & Member & Steel section & $\begin{array}{l}\text { End } \\
\text { conditions }\end{array}$ & $\begin{array}{l}\text { Length } \\
\text { (ft) }\end{array}$ \\
\hline \multirow{5}{*}{$\begin{array}{l}\text { Case I: } 6,12,18,24,27,30 \\
\text { stories }\end{array}$} & Column & $\mathrm{W} 10 \times 33$ & Continuous & 12.5 \\
\hline & $\begin{array}{l}\text { Exterior } \\
\text { braces }\end{array}$ & $\mathrm{W} 6 \times 20$ & $\begin{array}{l}\text { Pinned - } \\
\text { Pinned }\end{array}$ & 23.58 \\
\hline & $\begin{array}{l}\text { Exterior } \\
\text { beams }\end{array}$ & $\mathrm{W} 12 \times 60$ & $\begin{array}{l}\text { Pinned - } \\
\text { Pinned }\end{array}$ & 40 \\
\hline & Inside beams & $\mathrm{W} 12 \times 35$ & $\begin{array}{l}\text { Pinned - } \\
\text { Pinned }\end{array}$ & $\begin{array}{l}40 \text { and } \\
10\end{array}$ \\
\hline & $\begin{array}{l}\text { Horizontal } \\
\text { bracing }\end{array}$ & WT5 $\times 16.5$ & $\begin{array}{l}\text { Pinned - } \\
\text { Pinned }\end{array}$ & 14.14 \\
\hline \multirow{5}{*}{$\begin{array}{l}\text { Case II: } 6,12,18,24,27,30 \\
\text { stories }\end{array}$} & Column & $\mathrm{W} 10 \times 33$ & Continuous & 12.5 \\
\hline & $\begin{array}{l}\text { Exterior } \\
\text { braces }\end{array}$ & $\mathrm{W} 4 \times 13$ & $\begin{array}{l}\text { Pinned - } \\
\text { Pinned }\end{array}$ & 23.58 \\
\hline & $\begin{array}{l}\text { Exterior } \\
\text { beams }\end{array}$ & $\mathrm{W} 12 \times 60$ & $\begin{array}{l}\text { Pinned - } \\
\text { Pinned }\end{array}$ & 40 \\
\hline & Inside beams & $\mathrm{W} 12 \times 35$ & $\begin{array}{l}\text { Pinned - } \\
\text { Pinned }\end{array}$ & $\begin{array}{l}40 \text { and } \\
10\end{array}$ \\
\hline & $\begin{array}{l}\text { Horizontal } \\
\text { bracing }\end{array}$ & WT5 $\times 16.5$ & $\begin{array}{l}\text { Pinned - } \\
\text { Pinned }\end{array}$ & 14.14 \\
\hline
\end{tabular}
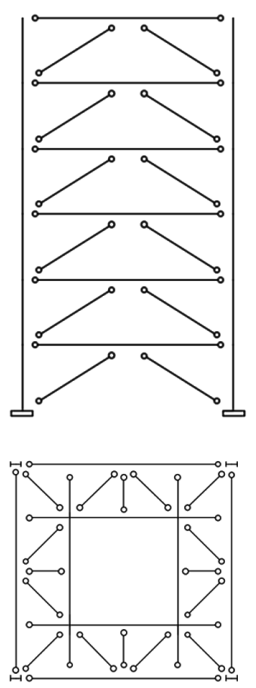

Fig. 3. Elevation and plan view of the model

dissipating energy. The use of right ductility and response modification factors can result in a safer and more cost effective structure than one designed using the elastic design force, which does not acknowledge the inelastic energy dissipating ability. 
ATC-19 proposed the following equations to formulate the response factor:

$$
\mathrm{R}=\Omega o * R \mu * \mathrm{Rr}
$$

where $\Omega o$ is the over strength factor, $\mathrm{R} \mu$ is the ductility factor, Ve is the force demand in the structure if the entire system remained linearly elastic, Vy is the maximum strength of the fully yielded system, and the Vd is the seismic base shear required for design.

The maximum lateral strength, Vy, generally exceeds the design lateral strength, Vd. This extra strength depends on many parameters that are not easily quantified. For instance, possible sources of this strength may result from the material strength if it is actually larger than the calculated design capacity. Other sources may be from nonstructural elements providing extra strength or from redistribution of internal forces in the inelastic range (ATC-19; Balendra T \& Huang). The Over strength $\Omega$ o can be idealized by Pushover curve as can be seen in Fig. 3. It can be expressed as the ratio of the maximum strength of the fully yielded system and the design shear strength.

$$
\Omega o=\mathrm{Vy} / \mathrm{Vd}
$$

\subsection{Ductility Factor, $R \mu$}

Structures lose their elastic behavior once a major yielding point occurs. The relationship between the system's elastic response and actual inelastic response can be seen in Fig. 3. The ratio between the maximum base shear due to elastic behavior and the yield base shear due to inelastic behavior is expressed by Ductility Factor, $\mathrm{R} \mu$, defined as:

$$
R \mu=\mathrm{Ve} / \mathrm{Vy}
$$

This non-linear behavior can be captured from Pushover and Nonlinear Dynamic Analyses

\subsection{Redundancy Factor}

The Redundancy factor, $\mathrm{Rr}$, measures the reliability of multiple vertical lines to transfer seismic-induced inertial force to the foundation (ATC-19). The following limitations apply to open frame structures may qualify for a reduction factor of 1.0 if there are four or more columns and three or more bays at each level. Otherwise, a factor of 1.3 shall apply.

\section{Numerical Simulations}

\subsection{Design of Model Structure}

The structures were modeled to be $40 \mathrm{ft} \times 40 \mathrm{ft}$ and had a combination of internal beams as well as horizontal bracing to account for the members that will hold up the 
grating that shall support personnel as they are completing their maintenance on the refineries. The elevation view illustrated in Fig. 3 shows the story height of every model structure which is fixed at $12.5 \mathrm{ft}$ and has chevron bracing. The columns are considered as hinged to the foundation. The design criterion, dead load of 0.1 kip per linear foot, was provided by Process Industry Practices, PIP STC01015, on the internal longitudinal beams and 0.05 kip per linear foot on the exterior longitudinal beams due to tributary area. A99 (Fy = $50 \mathrm{ksi}$ ) steel was utilized for every steel member of these OFS platforms. The chevron braces designed on these platforms are to account for the lateral seismic loads that the structure may experience.

\subsection{Nonlinear Static Analysis (Push over Analysis)}

Nonlinear static push-over analysis is conducted to determine the ultimate lateral load resistance as well as the sequence of yielding/buckling events. Eigen value analysis was conducted first to determine the elastic natural periods and mode shapes of the structure. Then pushover analysis were carried out to evaluate the global yield limit state and the structural capacity by progressively increasing the lateral story forces proportional to the fundamental mode shape.

Material nonlinearity is represented by hinges. Hinges form when members reach their moment or axial capacities. Moment curvature or force displacement interaction curves with post yield behavior are predetermined and can be used to determine hinge properties. For example, pure moment hinge with a $2 \%$ post yield slope is selected for moment beams. For axial members, axial hinges are selected. The hinges are strategically placed to predict possible hinge formation locations, which are usually near the joints between members. With the hinges placed and incremental lateral load applied, the model is then run to view the conceptual force capacity (Fig. 4).

\section{Tension}

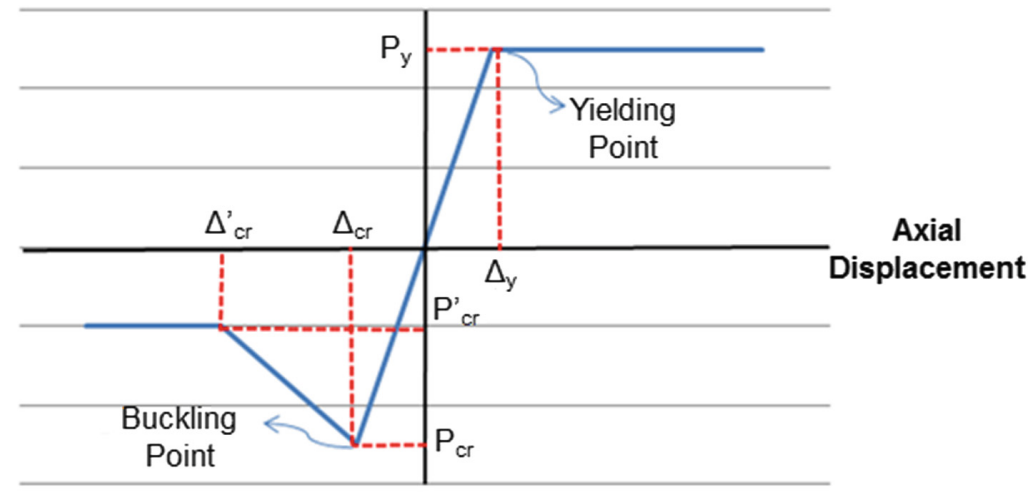

\section{Compression}

Fig. 4. Simplified analysis model for force-displacement relationship of brace 


\subsection{Nonlinear Dynamic Time - History Analysis}

Fast Nonlinear Dynamic Analysis, herein FNA, was used to conduct the Non-Linear Dynamic Analysis portion. The FNA method utilizes hinges as described in previous section in order to capture nonlinear material behaviour. With nonlinear behaviour placed in as hinges, it applies ground motions as modal applications. Modal application of acceleration time history ensures the runtime is short compared to other nonlinear dynamic analysis methods. The modal application is defined as Load-Dependent Ritz vector application in SAP2000. For each ground motion, the maximum displacement and base shear is obtained. The combination of all of the 22 ground motion results is called Incremental Dynamic Analysis. The Incremental Dynamic Analysis (IDA) results show a more realistic performance compared to the Pushover due to the dynamic application of real ground motions.

\subsection{Ground Motions}

To ensure broad representation of different recorded earthquakes, sets of ground motions contain records selected from all large magnitude events in the PEER NGA database. This study focus on the far field data. There are twenty-two far-field earthquake record sets specified in this database because it is a good representation of the strongest ground motion records which were selected from each event to permit statistical evaluation of record- to- record variability (FEMA P695). These earthquakes occurred between the timeframe 1971 through 1999 and were taken from fourteen of the largest events, eight of which occurred in California and six were from five different countries. Figure 5 illustrates the design and response spectra of all twenty two ground motions overlaid with design response Spectra that is prescribed currently in the ASCE-7 for the type of structure studied in this research. It should be notes that the 22

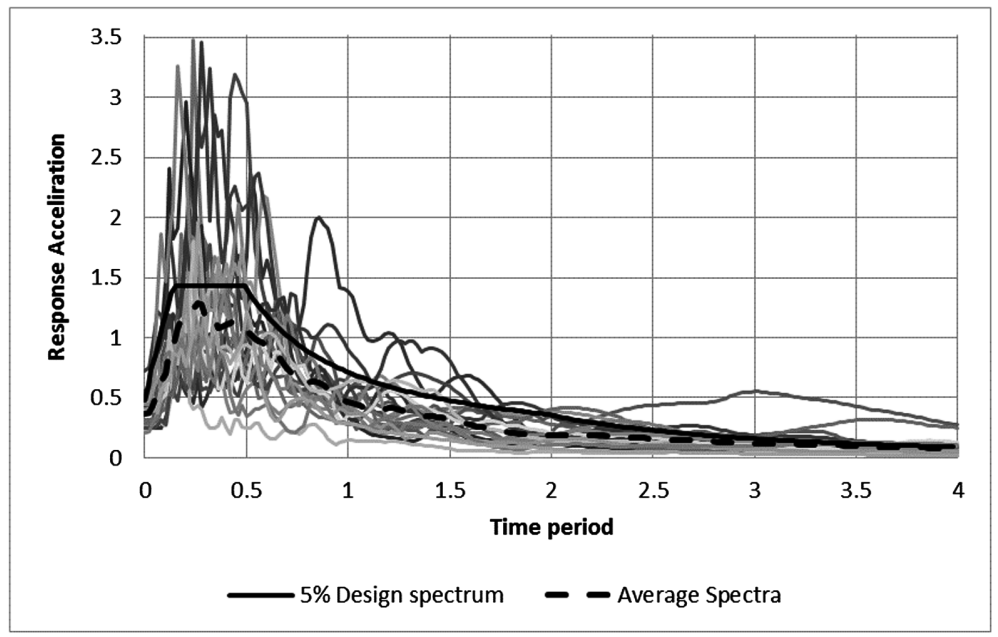

Fig. 5. Design spectrum and response acceleration of 22 selected ground motions 
found motions represent a variety of earthquakes that has different frequency contents and different peak ground accelerations.

\section{Results and Discussions}

With the parameters applied to the OFS platforms in design, the resultant nonlinear force-deformation (F-D) relationship could be obtained and provide insight into ductility and limit-state behavior. In order to find the parameters to calculate over strength and ductility, a straight line was drawn in such a way that the area under the original curve is equal to that of the idealized on recommended in FEMA-356 for structures with post-yield stiffness (Fig. 6).

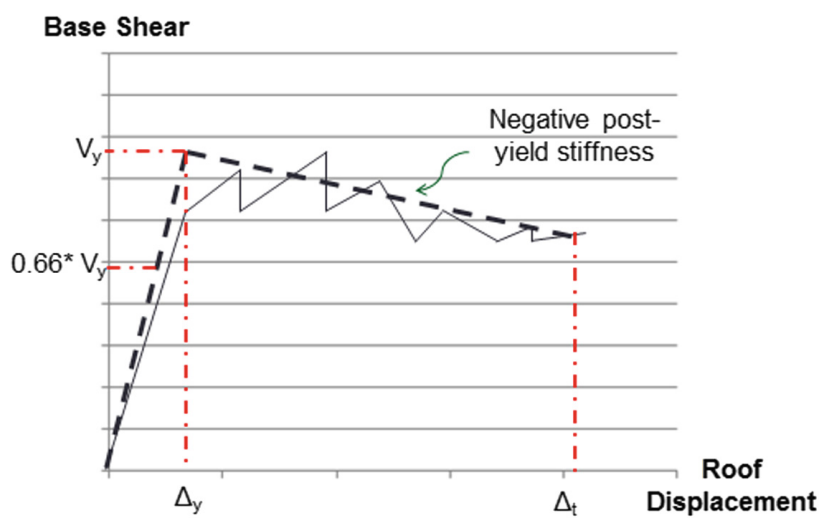

Fig. 6. Idealized curve for negative post-yield slope

The results are presented in Figs. 7, 8, 9 and 10 for the six OFS platforms, Fig. 7, illustrates a direct comparison of the pushover curve from Case I and Case II. Though post yield force reached the structure continues to have a positive slope the same ideology was taken in respect to FEMA-356. Results show that the weaker the members, the lower the shear experienced and the lower the deflection limit that can be applied to the force based structure. From these figures, the design base shear, yielding shear and the maximum seismic demand for the elastic response could be calculated for each case; resulting in the calculated $\mathrm{R}$ factors for this study, refer to Table 2.

The inelastic time-history analyses were conducted for both Case I and Case II of the OFS platforms which aided in the development of the structure's response curve. This curve was developed for each case study by plotting the maximum base shear and maximum top story drift for earthquake response. Figure 10 below, provides one example of the dynamic analysis results compared to the static pushover results for the 30 story OFS platform in Case I. The results indicate that the dynamic envelopes form below the yield point from the static nonlinear analysis; which will result in an even lower R factor for these structures. 


\section{Pushover}

\section{Roof Displacement VS Base Shear}

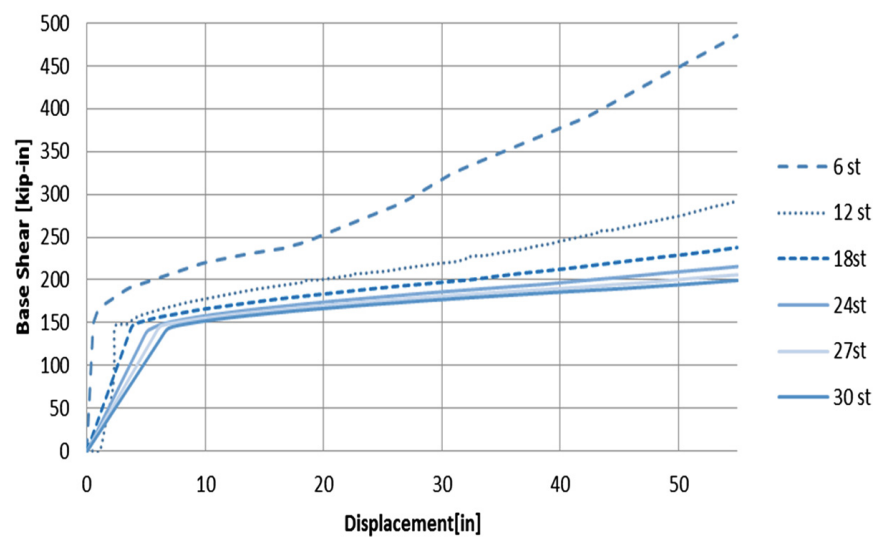

Fig. 7. Pushover curves of Case I structures

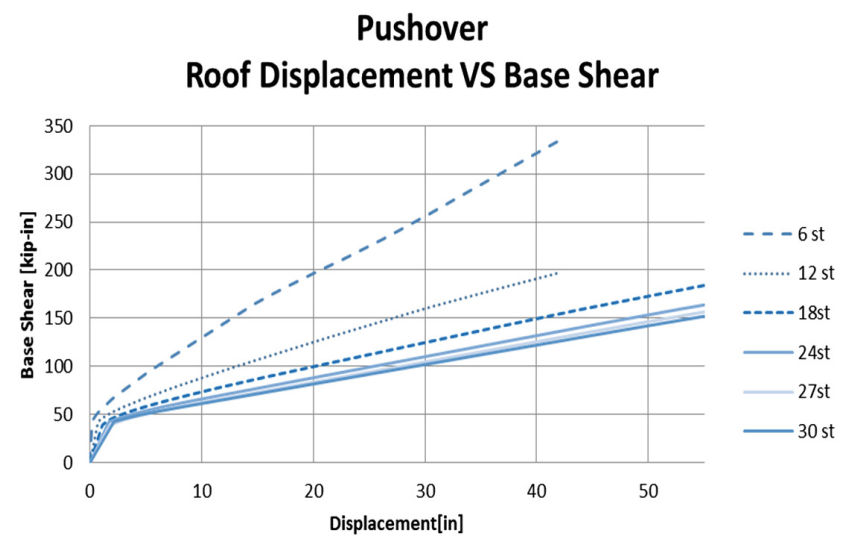

Fig. 8. Pushover curves of Case II structures

After the dynamic analysis was complete, the inter-story drift ratios of the OFS platforms were examined at the building corners and the results from the dynamic analysis are illustrated in Fig. 11. It is also noted that the inter-story drift angle is much smaller than the total inter-story drift angle, with larger deformation in lower stories and smaller deformation in higher stories.

The parametric study was performed to illustrate the variation in the seismic response modification factors of OFS platforms with different heights and the effects of having stronger braces, as illustrated by Case I and Case II. It also serves to compare the OFS platform's R factors to OCBF's R factor of 3.25, which is currently use as a 


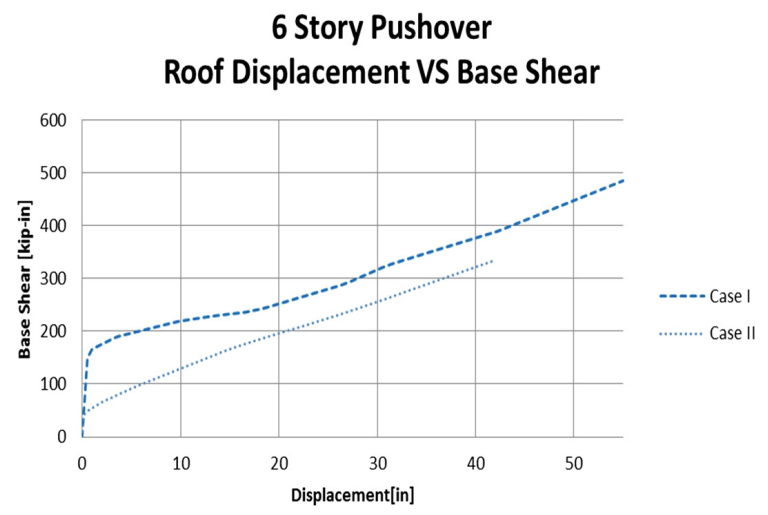

Fig. 9. Comparison of 6 story pushover curves with Cases I and II

\section{Story Dynamic vs. Static}

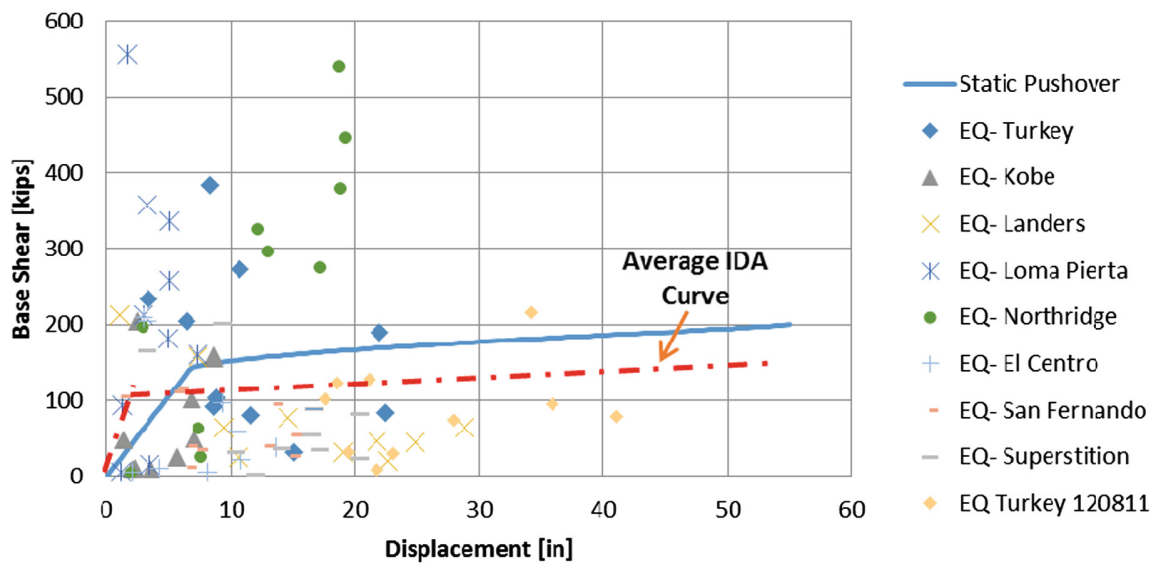

Fig. 10. Static and dynamic pushover curves of the Case I 30 story study

standard for these structures. In order to do this, the nonlinear static and dynamic analyses were utilized to produce the $\mathrm{R}$ factor. In practice, engineers have been using $\mathrm{R}$ factors of similar structures; however, OFS platforms are substantially different than typical building structures because there are several different design considerations to take into account. As a result of the nonlinear static analysis both cases I and II for stories $6,12,18,24,27$, and 30 had R factors below the OCBF's R factor of 3.2. This indicates that the structure is not capable of dissipating as much energy as the $\mathrm{R}$ factor of 3.25 assumes. Since Case I had a stiffer section for the brace, all studies experienced higher base shears which resulted in a lower average $\mathrm{R}$ factor of 1.5. Since the models in Case I were more stiff they had a low period and experienced more energy from the 
Table 2. Result of pushover analysis for model structure

\begin{tabular}{l|l|l|l|l|l|l}
\hline \multirow{2}{*}{} & \multicolumn{3}{|l|}{6 story } & \multicolumn{2}{l|}{12 story } & \multicolumn{2}{l}{18 story } \\
\cline { 2 - 7 } & Case I & Case II & Case I & Case II & Case I & Case II \\
\hline $\mathrm{V}$ & 96.392 & 29.666 & 95.394 & 28.19 & 94.948 & 26.778 \\
\hline $\mathrm{Vy}$ & 146.049 & 44.9491 & 144.537 & 42.712 & 143.86 & 40.573 \\
\hline $\mathrm{Ve}$ & 162.507 & 70.802 & 155.559 & 68.724 & 150.852 & 66.691 \\
\hline $\mathrm{Ru}$ & 1.11269 & 1.575 & 1.076 & 1.609 & 1.049 & 1.644 \\
\hline $\mathrm{Ro}$ & 1.515 & 1.515 & 1.515 & 1.515 & 1.515 & 1.515 \\
\hline $\mathrm{Rr}$ & 1 & 1 & 1 & 1 & 1 & 1 \\
\hline $\mathrm{R}$ & 1.686 & 2.387 & 1.631 & 2.438 & 1.589 & 2.49 \\
\hline & 24 story & 27 story & 30 story \\
\hline $\mathrm{V}$ & 98.954 & 28.145 & 94.505 & 25.058 & 92.103 & 27.921 \\
\hline $\mathrm{Vy}$ & 149.93 & 42.6441 & 143.189 & 37.9661 & 139.55 & 42.3051 \\
\hline $\mathrm{Ve}$ & 141.529 & 63.873 & 131.892 & 62.147 & 119.109 & 60.874 \\
\hline $\mathrm{Ru}$ & 0.944 & 1.498 & 0.916 & 1.637 & 0.854 & 1.4389 \\
\hline $\mathrm{Ro}$ & 1.515 & 1.515 & 1.515 & 1.515 & 1.515 & 1.515 \\
\hline $\mathrm{Rr}$ & 1 & 1 & 1 & 1 & 1 & 1 \\
\hline $\mathrm{R}$ & 1.43 & 2.269 & 1.388 & 2.48 & 1.293 & 2.18 \\
\hline
\end{tabular}

\section{Dynamic Interstory Drift: Story VS. Inter-Story Drift Ratio}

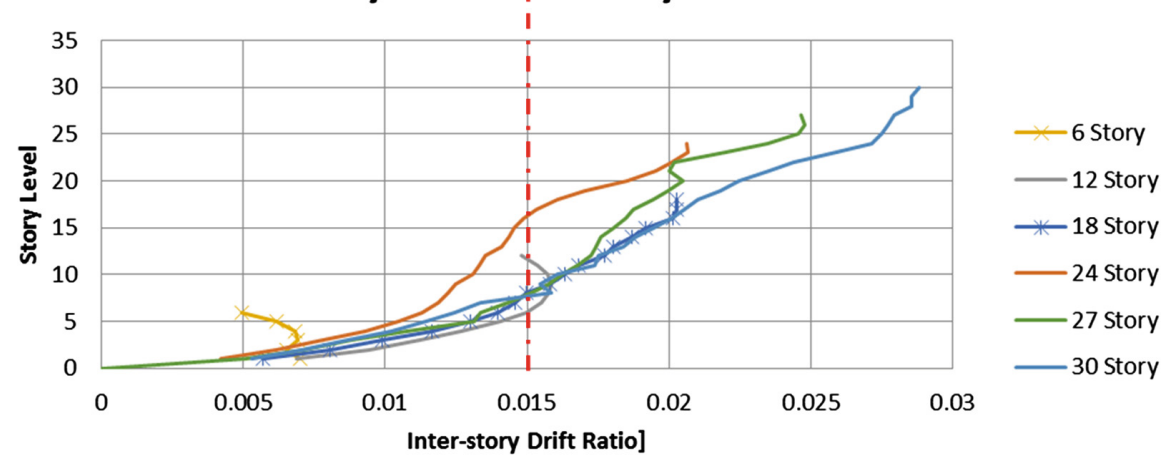

Fig. 11. Inter-story drift ratio of Case I studies

seismic events. In Case II which used a thinner section for the brace, the average $\mathrm{R}$ factor of 2.37 was computed. Since the structure was more flexible it was able to dissipate more energy than Case I. Therefore, in both cases, for all heights, ASCE 7-10 seemed underestimate the $\mathrm{R}$ factor. The $\mathrm{R}$ factor being used in practice today seems to be unsafe for these OFS platforms; especially for stiffer sections as seen from the results of this studies analysis (Fig. 12). 


\section{Response Modification Factor}

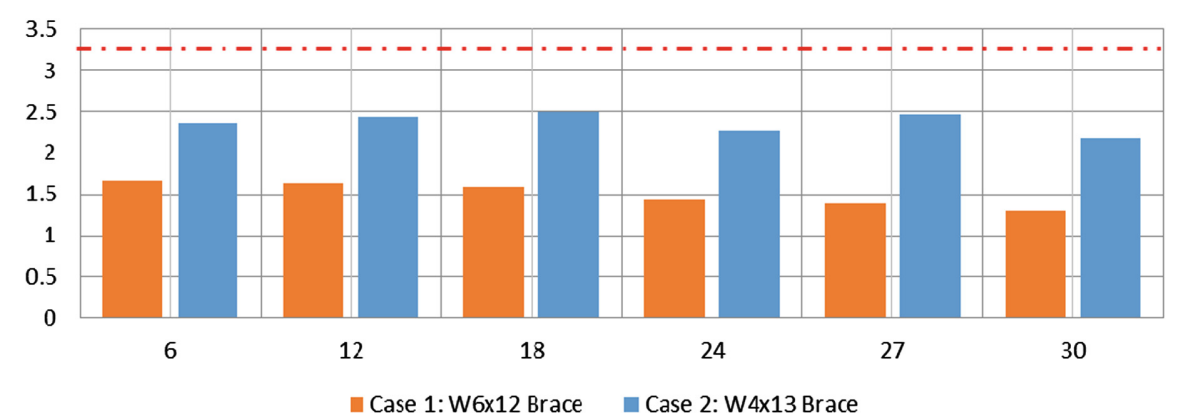

Fig. 12. R factor of Case I and II determined by nonlinear static pushover analysis

The nonlinear static analysis was also compared with the dynamic performance curve and the results illustrated that for the 30 story case study, yielding was reached at an earlier time and the response modification factor was decreased. However, both performance curves resulted in the same conclusion that the $\mathrm{R}$ factor used in the industry for OFS platforms, typically the R value for OCBFs of 3.25, over estimates the structure's energy dissipating capabilities. Lastly, the studies conducted illustrated that for both Case I and Case II, the story drifts of all structures taller than six stories were beyond the allowable drift limit set forth by ASCE 7-10.

\section{Conclusions}

From the analysis conducted, the $\mathrm{R}$ factor of the case studies decreased as the number of stories increased. Based on the results of this study, the current practice in designing these unique structures underestimates the value of the $\mathrm{R}$ factor for OFS platforms when they use the R factor of 3.25 for the ordinary concentric braced frames, especially when they are using stiffer sections. Underestimating a structures capability of dissipating energy may result in failures of structures and can risk public safety. It is recommended to continue to researching these structures by changing the parametric of the structure, span size, conducting a risk analysis, testing prototypes, and running numerical analysis to obtain a more accurate values of $\mathrm{R}$ factors for these structures.

Acknowledgments. The authors would like to acknowledge the support provided by the department of Civil Engineering at Cal Poly Pomona in offering the computer recourses that was necessary to conduct this study

\section{References}

Applied Technology Council, comp. FEMA P695: Quantification of Building Seismic Performance Factors. FEMA (2009, print) 
ASCE: ASCE/SEI 7-10: Minimum design loads for buildings and other structures. Standard Committee, American Society of Civil Engineers, Reston, Virginia (2005)

ATC: Structural response modification factors, pp. 5-32. ATC-19, Applied Technology Council, Redwood City, California (1995)

Balendra, T., Huang, X.: Overstrength and ductility factors for steel frames designed according to BS 5950. J. Struct. Eng. 129(8), 1019-1035 (2003). ASCE

Kim, J., Choi, H.: Response modification factors of chevron-braced frames. Eng. Struct. 27(2), 285-300 (2005). ISSN 0141-0296

Harris, J.R., Rutz, F.R., Manouri, T.: FEMA (n.d.). http://c.ymcdn.com/sites/www.nibs.org/ resource/resmgr/bssc/p751_ch6.pdf. Web: 14 Mar 2016

Mahmoudi, M., Zaree, M.: Determination the Response Modification Factors of Buckling Restrained Braced Frames. Elsevier Ltd., Tehran (n.d., print)

National Institute of Building Sciences Building Seismic Safety Council, comp. FEMA P751: 2009 NEHRP Recommended Seismic Provisions: Design Examples (2012, print)

SEAOC Seismology Committee: A brief guide to seismic design factors. Struct. Mag. 30-32, September 2008

SEAOC Seismology Committee: Seismic force-resisting systems part 1: seismic design factors. Struct. Mag. 27-29, January 2009

Seismic Design, Assessment and Retrofitting of Concrete Buildings. Google Books (2009). Web: 8 Mar 2016

Static Pushover Analysis, SAP 2000, Computer Structure, Inc. https://www.csiamerica.com/ products/sap2000/watch-and-learn

Salem, Y.S., Nasr, M.A.M.: Evaluating response modification factors of open frames steel platforms. In: Tenth U.S. National Conference on Earthquake Engineering 